\title{
Dedication to Professor Leslie Z. Benet: 50 Years of Scientific Excellence and Still Going Strong!
}

\author{
David E. Smith • Malcolm Rowland $•$ Kathleen M. Giacomini • Gordon L. Amidon
}

Received: 11 June 2012 / Accepted: 11 June 2012 / Published online: 20 July 2012

(C) Springer Science+Business Media, LLC 2012

\section{PROFESSOR LESLIE Z. BENET: BIOGRAPHY AND SUMMARY OF MAJOR ACCOMPLISHMENTS}

\section{Professor and Former Chair}

University of California San Francisco

Department of Bioengineering and Therapeutic Sciences

Department of Pharmaceutical Chemistry

\section{Research Expertise}

- Pharmacokinetics and Pharmacodynamics

- Biopharmaceutics and Drug Delivery

- Drug Metabolism

- Drug Transporters

\section{Education}

- BA, English, University of Michigan (1959)

- BS, Pharmacy, University of Michigan (1960)

- MS, Pharmaceutical Chemistry, University of Michigan (1962)

- PhD, Pharmaceutical Chemistry, University of California San Francisco (1965)

Values for h-index and citation number were determined by Thomson Reuters Web of Knowledge on June 4, 2012.

\section{E. Smith $(\square)$}

Department of Pharmaceutical Sciences, College of Pharmacy University of Michigan

4742C Medical Sciences II, I 50 W. Medical Center Drive Ann Arbor, Michigan 48I09-5633, USA

e-mail: smithb@umich.edu

\section{Rowland}

School of Pharmacy and Pharmaceutical Sciences

University of Manchester

Manchester, United Kingdom

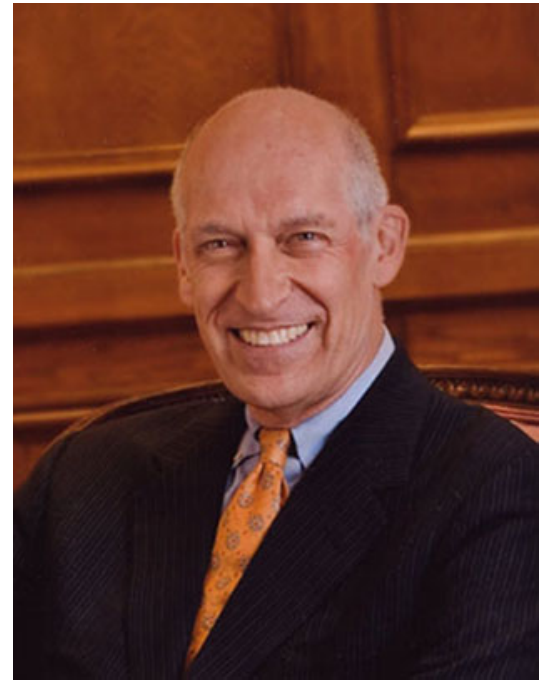

\section{K. M. Giacomini}

Department of Bioengineering and Therapeutic Sciences School of Pharmacy, University of California

San Francisco, CA, USA

\section{G. L. Amidon}

Department of Pharmaceutical Sciences, College of Pharmacy University of Michigan Ann Arbor, Michigan, USA 


\section{Honorary Degrees}

- Uppsala University, Sweden (PharmD, 1987)

- Leiden University, The Netherlands (PhD, 1995)

- University of Illinois at Chicago (DSc, 1997)

- Philadelphia College of Pharmacy and Science (DSc, 1997)

- Long Island University (DSc, 1999)

- University of Athens, Greece (PhD, 2005)

- Catholic University of Leuven (PhD, 2010)

- University of Michigan (DSc, 2011)

\section{Scientific/Professional Honors and Awards}

- Distinguished Alumnus Award, University of Michigan College of Pharmacy (1982)

- Research Achievement Award in Pharmaceutics, Academy of Pharmaceutical Sciences (1982)

- Election to the Institute of Medicine of the National Academy of Sciences (1987)

- Distinguished Service Award, American College of Clinical Pharmacology (1988)

- Distinguished Scientist Award, American Association of Pharmaceutical Scientists (1989)

- Rho Chi Society Lecture Award, The Rho Chi Society (1990)

- Volwiler Distinguished Research Achievement Award, American Association of Colleges of Pharmacy (1991)

- Distinguished Service Profile Award, American Foundation for Pharmaceutical Education (1993)

- Rawls-Palmer Progress in Medicine Award, American Society for Clinical Pharmacology and Therapeutics (1995)

- Distinguished Service Award, American Association of Pharmaceutical Scientists (1996)

- Takeru Higuchi Research Prize, American Pharmaceutical Association (2000)

- Wurster Research Award, American Association of Pharmaceutical Scientists (2000)

- Host-Madsen Medal, International Pharmaceutical Federation (2001)

- Research Achievement Award in Pharmaceutical Sciences, Pharmaceutical Sciences World Congress (2004)

- Career Achievement Award in Oral Drug Delivery, Controlled Release Society (2004)

- Distinguished Clinical Research Lecturer, UCSF (2007)

- Oscar B. Hunter Memorial Award in Therapeutics, American Society for Clinical Pharmacology and Therapeutics (2010)

- Distinguished Investigator Award, American College of Clinical Pharmacology (2011)

\section{Teaching Awards}

- Academic Senate Distinguished Teaching Award, UCSF (1973)

- Long Teaching Award for Excellence in Teaching, UCSF School of Pharmacy (1990)

- Outstanding Faculty Mentorship Award, UCSF Graduate Division (2001)

\section{Publications and Impact}

- Peer-Reviewed Publications: $>400$

- Book Chapters: > 100

- Books: 7

- Patents: 11

- Thomson ISI Highly Cited Researcher

- H-Index: 64

- Mentored >50 Doctoral Students and >100 Professional, Postgraduate, and Postdoctoral Research Personnel and Scholars

- Founder and First President, American Association of Pharmaceutical Scientists (1986) 


\section{INTRODUCTION}

\section{BY DAVID E. SMITH}

Professor Leslie Zachary Benet was born May 17, 1937 in Cincinnati, Ohio, back in the days when Leslie was a man's name. He was born into a family of pharmacists. His father, Jonas, and Uncle Harry Benet had worked as delivery boys for a local pharmacy and decided to pursue the pharmacy profession. Harry graduated as a pharmacist from the University of Kentucky and Jonas from the Capitol College of Pharmacy in Denver, where he was a classmate of the only health professional to serve as a United States Vice President, Hubert H. Humphrey. Harry and Jonas opened Benet's Pharmacies in Cincinnati, Ohio, in the 1930s. From the beginning, it almost exclusively dispensed prescription drugs and specialty products that they manufactured. In the 1940s they founded DARA Products, the first drug company to make hypoallergenic dermatologicals. One of their secrets was changing the $\mathrm{pH}$ of the preparations to 7.4, which made the shampoo amphoteric and sold as a "soapless" shampoo.

The family plan was for Les to go to pharmacy school, then get a graduate degree and come home and run DARA Products. This clashed with Les's goal of going to Yale as an English major followed by graduate school and then becoming an academic in the Humanities. However, the family won out, and in the fall of 1955, Les enrolled in the College of Pharmacy at the University of Michigan. Still, Les kept up his strong interest in English literature and creative writing. During his undergraduate years, Les waivered back and forth between English and Pharmacy. At the end of his third undergraduate year he decided to complete his degree in English, with the thought of pursuing graduate education in that discipline. Les fancied himself as a poet and enrolled in many creative writing classes, where he excelled. However, the best outcome of his period as a full-time English major was meeting his future wife, Carol Levin, also an English major. In the spring of 1959 of his senior year as an English major at the University of Michigan, Les asked one of his creative writing teachers, Professor Donald Hall (who subsequently went on to become Poet Laureate of the United States) to give him an honest evaluation of his capabilities. Mr. Hall asked Les for his writing portfolio and they met again 2 weeks later, when the conversation ensued with $\mathrm{Mr}$. Hall saying something like, "Les, I've had you in class and you have been a pleasure to have as an excellent student.
In addition, I know that you have interest in being an academic and I think you will do an outstanding job as a faculty member. However, I have reviewed your portfolio and I must tell you honestly, you will never be a poet." Les has told me that he was very appreciative of Mr. Hall's willingness to give a frank critique, which in his heart he already knew. Thus, Les made plans to re-enroll in pharmacy school and, immediately after he received his Bachelor of Arts as an English major from the University of Michigan in 1959, did so.

The following year, 1960, Les received his Bachelor of Science in Pharmacy. Early in his undergraduate training, Les began to carry out research in the laboratory of Assistant Professor Ara Paul and gained an appreciation and an attraction to basic research. During his undergraduate Pharmacy Training, Les was particularly intrigued with the mathematical and physical chemistry basis of the courses in Physical Pharmacy then taught by Assistant Professor Jere Goyan. In 1960, he entered the Pharmaceutical Chemistry Graduate Program at the University of Michigan working under Professor Goyan deriving basic principles for the dissociation of multivalent acids and investigating the thermodynamics of tetracycline chelation. Les was Jere Goyan's first graduate student and Jere held the belief, not so unusual in 1960, that Ph.D. scientists should be able to construct the instrumentation upon which they carried out their work. Thus, Les was required to make a $\mathrm{pH}$ meter. It worked well, except for some grounding problems, and Les called it the "no shoe $\mathrm{pH}$ meter," which he operated barefoot. He then went on to build a calorimeter that he used to measure the thermodynamics of chelation by tetracyclines, his Ph.D. thesis topic.

During his graduate training, Les took courses in advanced mathematics, physical chemistry, and chemical engineering unit operations, but very little biology and pharmacology. Dr. Goyan was recruited to the University of California San Francisco (UCSF) at the end of Les's third year of graduate school, and Les accompanied Jere to San Francisco. However, once at UCSF, Les had to remediate his minimal training in the biological and pharmacological sciences, since he was required to retake his qualifying exams at his new institution. In 1965, he received his Ph.D. in pharmaceutical chemistry from UCSF. Upon graduation, Les chose not to do a postdoctoral fellowship, since he had two academic job offers and was recruited to Washington State University (WSU) in the fall of 
1965 to teach physical pharmacy and pharmaceutical analytical chemistry. He discovered that what he knew about $\mathrm{pH}$ could be useful in understanding drug absorption, and his first NIH grant on $\mathrm{pH}$ effects in drug absorption was funded 9 months after he joined the WSU faculty.

Les has recently written the backstory of how he became a pharmacokineticist (1), but when recruited back to UCSF as a faculty member in 1969 he filled a physical pharmacy teaching position because no one at UCSF thought he knew any biology/pharmacology.

\section{THE EARLY YEARS (1965-1979) BY MALCOLM ROWLAND}

I first met Professor Leslie Benet at the 1968 annual meeting of the Academy of Pharmaceutical Sciences in Dallas, where he was presenting an oral communication on volume terms in pharmacokinetics, an area of science that had only been coined 15 years earlier. I listened due to my own interest in pharmacokinetics, but also as I had heard that he would be leaving WSU Pullman to join me at the Department of Pharmacy, School of Pharmacy, UCSF, chaired by Sidney Riegelman. His enthusiasm and lively presence shown then are hallmarks that have stayed with him throughout his career. Les took up his appointment at UCSF in 1969, having previously been steeped in physical pharmacy, publishing on stability constants of complexes and potentiometric determination of dissociation constants (2). While he was responsible for teaching physical pharmacy, it was very clear that Les's research interests were increasingly gravitating to biology, aided by the UCSF environment, with the School of Pharmacy part of the Health Science complex, rich in biomedical research.

These were the early days of biopharmaceutics, and on the experimental side Les pursued research into intestinal drug absorption, initially involving in vitro mechanistic studies but soon widening to in vivo animal models and studies in healthy volunteers, primarily centered on physiological considerations (3), which were to be followed later in his career by his seminal work on the role of enzymes and transporters on drug absorption. This spread, from mechanistic studies to clinical application was, and has remained, a central hallmark of Les's research.

Les also turned his attention to various theoretical aspects of pharmacokinetics, which in those days was heavily focused on linear systems, and he became well known for his now familiar "hidden hand" approach to the time varying solution of Laplace transforms (4). He continued to explore further aspects of volume of distribution, culminating in the paper on noncompartmental determination of this parameter (5), which remains one of the most cited papers in pharmacokinetics. During these early years, Les and I had many discussions, one of which led to the application of twocompartment models to the analysis of drug and metabolite data (6), models that were only then beginning to be applied to such data. But the most fruitful discussions were the ones following Les coming into my office one day and saying words to the effect of "Let's talk more about clearance," which culminated in our clearance concept paper (7), the first to quantitatively relate blood flow and cellular activity to clearance, using what is now commonly known as the wellstirred physiological model of clearance. This very highly quoted paper laid the foundation for fruitful research and wide application of this concept in drug discovery, development and therapeutic use. The other important facet associated with this 1973 publication was that it appeared in the second issue of a new journal, the Fournal of Pharmacokinetics and Biopharmaceutics (subsequently renamed Fournal of Pharmacokinetics and Pharmacodynamics), founded by Sid Riegelman, with Les and me as Associate Editors. Les then took on the main burden as Editor of this premier journal for cutting-edge developments in the subject.

One important research link established in 1969 was between the Department of Pharmacy and the Division of Clinical Pharmacology, School of Medicine, chaired by Kenneth Melmon. This brought Les into contact with a variety of clinical pharmacology fellows, including Lewis Sheiner and Carl Peck, and deepened the contributions that Les made to clinical pharmacology and which helped make UCSF a mecca for pharmacokinetics and pharmacodynamics. While I could list several papers that emerged from this collaboration during the period 1970 to 1979, in my opinion the most significant was the one on the relationship between pharmacokinetics and pharmacodynamics of procainamide (8), as it introduced the now well-known "hysteresis" plot, and the forerunner of the "link" pharmacokinetic/pharmacodynamic model, to explore the temporal relationship between measured concentration and response.

I have been privileged to know Les as a research colleague and dear friend for the past 40 years. Throughout, he has been a towering figure in pharmacokinetics, and the pharmaceutical sciences in general, not only in research but also in teaching, professional service, and in professional societies, such as the American Association of Pharmaceutical Scientists and International Pharmaceutical Federation. Les epitomizes the very best, and I look forward to the many more important contributions that I am sure he will make in the coming years.

\section{THE FORMATIVE YEARS: 1980-1989 BY DAVID E. SMITH}

During this period of time, Professor Leslie Benet developed a number of research themes that were instrumental in 
defining the pharmacokinetics and pharmacodynamics of important therapeutic drugs, pharmacologic and immunologic concepts, and drugs in disease populations. In particular, he pioneered several novel investigations, including 1) the determinants of diuretic response (e.g., furosemide, triamterene, and hydrochlorothiazide); 2) the kinetic-dynamic relationship of corticosteroid and immunosuppressive agents (e.g., prednisone, prednisolone, and cyclosporine); 3) the pharmacokinetics and metabolism of nitroglycerin; 4) the mechanisms of intramolecular acyl-glucuronide migration and reactivity (e.g., zomepirac, benoxaprofen, and tolmetin); and 5) new approaches to analyze complex pharmacokinetic data. Whereas each category is a treatise onto itself, I have chosen to highlight one manuscript from each of the five categories as an example of Les's impact in the pharmaceutical and biomedical sciences.

Prior to the publication by Smith et al. (9), data concerning the metabolism and pharmacokinetics of furosemide (a loop diuretic) were controversial primarily because of the lack of a sensitive and specific assay method. This paper provided the definitive absorption and disposition properties of furosemide in healthy subjects, along with its in vivo plasma protein binding. Moreover, the assay method provided a solid foundation for subsequent studies in which the effect-concentration relationship of furosemide was evaluated through innovative drug-interaction studies with probenecid and indomethacin, and in kidney transplant patients.

The pharmacokinetics of prednisolone (a corticosteroid) were complex for a number of reasons, including its reversible metabolism with prednisone. The publication by Legler et al. (10) was significant in conclusively demonstrating that, under steady-state conditions, prednisolone exhibited doseand concentration-dependent kinetics in humans and that this phenomenon was primarily due to saturable plasma protein binding of the drug. The knowledge gained from this study paved the way for important clinical studies of prednisolone kinetics in patients on hemodialysis, patients with Cushing's disease, and women taking oral contraceptives.

Using a sensitive and specific analytical method for the measurement of nitroglycerin and its dinitrate metabolites, Noonan et al. (11) clearly demonstrated the disproportionate increase in plasma concentrations with increasing infusion rate (i.e., nonlinearity) and the incongruent clearances of nitroglycerin when the same infusion rate was administered at the beginning and end of the study design. This unusual observation was important because depending upon the length of drug infusion, and the increasing 1,2- and 1,3glyceryldinitrate metabolites, greater than expected steadystate plasma concentrations of nitroglycerin would be observed along with greater vasodilation (and potential toxicity) of parent drug and accumulated active metabolites.

Smith et al. (12) documented, for the first time, the in vivo covalent binding of zomepirac glucuronide to albumin along with in vitro evidence for isomers of zomepirac glucuronide binding to albumin irreversibly by intramolecular acyl migration. Being a nonsteroidal anti-inflammatory drug (NSAID) that was withdrawn from the market in 1983 because of unexplained anaphylactic reactions, and the large and growing sales of NSAIDs in general, the formation of acyl glucuronide adducts with tissue proteins, leading to potential haptens, was a significant drug safety concern.

The early-to-mid 1980s produced an explosion of papers dealing with basic concepts related to the use of statistical moment theory and its application to mean residence times of the whole body and body compartments, clearance, and volume of distribution. Along with this explosion came many misconceptions, confusion, and controversy. The paper by Nakashima and Benet (13) provided a thoughtful, clear, and detailed analysis of this topic, thereby clarifying the interrelationship between compartmentally and noncompartmentally derived pharmacokinetic parameters, in which first-order elimination could occur from compartments other than the central compartment of a mammillary model.

Overall, I view this period as one of transition for Les from the pharmaceutical sciences of specific drugs to the science of biomedical concepts. In effect, his manuscripts represent an outstanding period of scientific growth and redirection from his roots in the physical-chemical sciences into the emerging sciences of biopharmaceutics and pharmacokinetics. Moreover, it is evident that a new science is taking shape, long before the term "translational research" became fashionable, that of testing basic concepts in the clinics and then translating the results into medical practice (i.e., from bench to bedside).

During Les's distinguished career, he served as a mentor for more than 100 professional, postgraduate, postdoctoral researchers and scholars, and over 50 graduate students, of which I was the twelfth. Joining his laboratory was a professional awakening for me, one in which I experienced tremendous growth in scientific thought, research experience, and, perhaps most of all, confidence. In just three short years, I was beginning to think past my specific project on the pharmacokinetics of furosemide and into the physiological-pharmacological concepts of drug transport in the kidney and mechanism-based drug transport in general. The ability to think conceptually, mechanistically, and translationally would serve me well for my entire scientific career. However, what I most appreciate about Les is his mentorship past science. This continues today. In my view, he is one of very few professors in the pharmaceutical sciences who are exceptional in the trinity of academia: teaching, research, and service. On a more personal note, I greatly admire the kindness, warmth, and respect Les shows to his colleagues, students, friends, and 
competitors. It is truly remarkable and another example of what a role model should aspire to. Finally, I would be remiss if I did not thank Les for his tremendous sense of humor. Without going into detail, suffice it say my professional and scientific life would be very different if this were not the case.

\section{THE POWER YEARS: 1990-1999 BY KATHLEEN M. GIACOMINI}

During this time, a reductionist approach to pharmacological research prevailed. Advances in molecular biology began to be applied to a myriad of pharmacologic problems. For example, the molecular identities of many proteins important in pharmacokinetics and pharmacodynamics were discovered through molecular cloning and recombinant DNA methods. Though Professor Leslie Benet did not jump on the molecular biology bandwagon, increasingly, he began to focus on understanding the biological mechanisms that determined pharmacokinetic properties. In particular, his research gravitated towards intestinal drug absorption and elimination and the proteins involved in these processes. Two major concepts emerged from his research during this time, both of which had a major impact on clinical pharmacology and drug development sciences: 1) intestinal drug metabolism and 2) enzyme transporter interplay. The discussion below focuses on these two concepts, though Les continued to make other notable contributions during this time. In particular, he co-authored a highly cited manuscript on gender effects in pharmacokinetics and pharmacodynamics (14). Importantly, the body of work on reactive and potentially toxic acyl glucuronide metabolites continued with a highly cited paper "Acyl glucuronides revisited: is the glucuronidation process a toxification as well as a detoxification mechanism?"(15).

Though considerable progress had been made in understanding the major role of the liver in drug metabolism, few studies focused on oral drug absorption and, in particular, intestinal metabolism. Intestinal drug metabolism was considered minor in comparison to hepatic drug metabolism. Continuing his career focus on immunosuppressive agents, Les co-authored several papers showing that cyclosporine bioavailability increased with high fat meals. Importantly, he and his colleagues published a paper in 1995 (16) in which they reanalyzed previous data from their laboratory, showing that poor bioavailability of cyclosporine was a result of high intestinal first-pass metabolism, not poor absorption. This highly cited paper provided a theoretical framework for predicting intestinal drug metabolism and demonstrated that intestinal, not hepatic, first-pass metabolism was the primary source of the low bioavailability of cyclosporine. Equations and concepts developed in the Benet laboratory during this time have been incorporated in modern physiologically based pharmacokinetic modeling to predict bioavailability (17). His research shifted the paradigm from the idea that first-pass metabolism occurred predominantly, if not exclusively, in the liver, to the idea that the intestine may play a major role in first-pass metabolism of many drugs.

Les's most notable scientific concept emerged during the 1990s as he began to consider the particular enzymes and transporters that played a role in drug absorption and disposition. Functional characteristics of enzymes and transporters, many of which had been recently cloned, were his focus. A compendium of drug-enzyme and drugtransporter interactions was being developed; however, few investigators thought about how these two major classes of proteins interacted to mediate drug elimination. In a series of elegant studies, Les and his colleagues proposed and tested the concept that intestinal drug metabolism was most efficiently accomplished when an efflux transporter worked together with a drug metabolizing enzyme. In the absence of an efflux transporter, a drug would enter the epithelial cells, and though a fraction of it would be metabolized, much would escape metabolism entering the portal circulation in the unmetabolized form. However, in the presence of an efflux transporter such as $\mathrm{P}$-glycoprotein (P-gp), unmetabolized drug that entered the intestinal epithelium would be pumped back into the intestinal lumen and would have multiple opportunities to re-enter the intestinal epithelium and undergo intestinal drug metabolism. This concept, which Les termed transporter-enzyme interplay, was described in several highly cited articles published in the 1990s, most notably papers by Wacher et al., cited 599 times (18); Lown et al., cited 502 times (19); Wacher et al., cited 283 times (20); and Wu et al., cited 248 times (16). Subsequent studies in the past decade expanded on these concepts, and collectively this body of work resulted in an integrated understanding of the pharmacokinetic systems that are responsible for drug absorption and elimination. Les's work on transporter-enzyme interplay represented one of our earliest concepts of a multi-protein pharmacologic system. Subsequent research in systems biology has revealed that transporters and enzymes are part of complex co-expression networks (21).

For over 20 years, Les chaired the Department of Pharmacy at UCSF which, under his leadership, became the Department of Biopharmaceutical Sciences. During his tenure as chair, he recruited, hired, and mentored a young and promising cast of academic pharmaceutical scientists, including Frank Szoka, Deanna Kroetz, Richard Guy, and myself. In addition, Wolfgang Sadée and Thomas Tozer developed their careers largely under Les's leadership. The academic environment reflected Les's personal qualities and leadership style: warm, engaging, and highly stimulating. The pharmaceutical sciences were thriving, and Les was the 
clear leader in the field. In addition, Les promoted an environment of entrepreneurship, encouraging researchers to perform translational research, transforming their discoveries into therapeutic advances. In particular, several faculty members, including Les, started their own companies. The relationship between faculty in the department and the biotechnology and pharmaceutical industry sectors grew. For young faculty members, Les was also the leader of a large Center Grant, Drug Kinetics and Dynamics Center, funded by NIGMS from the late 1970s until 1998. Les used the Center Grant to facilitate the research careers of his junior faculty members. The Center provided a mechanism for them to obtain funding for their research, riding on the enormous reputation and scholarship of Les. Though Les was clearly in his "power years," he made time for mentoring his faculty and for the department, which emerged as a world-class department in the pharmaceutical sciences.

\section{THE SENIOR YEARS: 2000-20I2 BY GORDON L. AMIDON}

Professor Leslie Benet's scientific contributions for the past decade plus entail more than 122 papers: more than 10 per year is a substantial and intimidating reading assignment for even an avid reader of scientific literature. We are fortunate to have such a prolific, personable, and charismatic scientist and leader in the field of pharmaceutical sciences. I will notindeed, cannot - do complete justice to this time period of overwhelming productivity. I will select those publications that are related closely to my own expertise in biopharmaceutics and which, in my view, are a great leap forward, if not revolutionary, in the conceptual advances they have made in the fields of biopharmaceutics and pharmacokinetics.

The prolific productivity of Les over the years, and continuing through today, is no doubt a result of his personality, his collaborators, and his impressive breadth and depth of knowledge in the pharmacokinetic and drug metabolism fields. Les's productivity during this period can be broadly classified into 1) metabolism, 49 publications; 2) pharmacokinetics, 24 papers; 3) transporters, 28 papers; 4) biopharmaceutics, 15 papers; 5) pharmacodynamics, 14 papers; 6) metabolismtransporter interaction, 13 papers; and 7) analytical, 5 papers, with numerous papers fitting multiple categories.

During this period, of particular note are the metabolic enzyme-transporter interaction papers that focus on the cellular availability of drug to metabolic processes in the cell and to the polarity and orientation of the epithelial cell in the intestine, liver, and kidney (22-25), and to the Biopharmaceutics Drug Disposition Classification System (BDDCS) series of papers (26-28). These papers truly encompass major conceptual leaps in biopharmaceutics and pharmacokinetics, and our understanding of absorption, distribution, metabolism, and excretion (ADME) drug properties.

The concept of transporter and metabolic enzyme interaction as developed by Benet et al. (29-31) in both the intestinal epithelial cell and liver hepatocyte, and the inverse orientation of P-gp and cytochrome P450 isoform 3A4 (CYP3A4) in those tissues, adds a new mechanistic understanding to intravenous and oral pharmacokinetics, first-pass metabolism and oral bioavailability, and drug-drug interactions. It provides a template for predicting enzyme-transporter (both absorptive and efflux) interactions in the intestine and liver. The synergistic effects of CYP3A4-mediated metabolism and P-gpmediated efflux on intestinal first-pass metabolism, or the recycling hypothesis as proposed by Les, is an original mechanistic insight into particular first-pass metabolism observations.

The 2005 BDDCS paper, in particular, truly advances and conceptualizes a new era of molecular ADME. Wu and Benet (26) developed the concept of molecular ADME, although not stated as such in that paper, and made multiple predictions. The marvelous breadth and depth of knowledge and insight required to see this organizing ADME principle is truly remarkable. The insight to see that Class I and II drugs of the Biopharmaceutics Classification System (BCS) are eliminated by metabolism and that Class III and IV drugs of the BCS are eliminated by biliary and/or renal excretion is a concept that allows us to look at a drug molecule and with computational systems "in silico" form hypotheses as to how that potential drug will be handled by the body. In fact, Les has done this with over 900 new molecular entities, "drugs" (28-32). To see this ADME organizing principle required a scientist with a very broad knowledge and experience in drug metabolism and pharmacokinetic elimination.

Here I must add a personal note. I can say that when I looked at the fraction absorbed $\left(\mathrm{F}_{\mathrm{abs}}\right)$ vs. intestinal (jejunal) permeability plot in rat jejunum (33) or human jejunum (34), I could see that the curve, if done using systemic availability $\left(\mathrm{F}_{\text {sys }}\right)$, became very erratic for drugs with permeabilities above metoprolol. However, for drugs with permeabilities below metoprolol, $\mathrm{F}_{\text {abs }}$ and $\mathrm{F}_{\text {sys }}$ were essentially the same. In fact, that is why $\mathrm{I}$ turned to $\mathrm{F}_{\mathrm{abs}}$ from $\mathrm{F}_{\text {sys }}$ vs. permeability in the mid-1980s (33). Thus, Les's 2005 paper on BDDCS came as a profound revelation to me; I could not see what Les saw in our own publication (35). BDDCS is our first organizing principle for the DME part of ADME. While the pharmacokinetic field exploded beginning from about 1960, it has mainly focused on descriptive kinetics of an individual drug and the processing in specific tissues, e.g., liver, kidney, and brain. With this 2005 BDDCS paper, we have our first overarching pharmacokinetic and metabolism organizing principle. I believe this 2005 
BDDCS paper is a seminal concept and development in the field of molecular ADME of drugs and will have a profound impact on drug discovery and development in the 21 st century, and, eventually human health and quality of life.

Two papers that may not have received the attention they deserve are related to dosing half-life and dosing interval $(36,37)$. All too often, dosage forms, especially immediate release oral dosage forms, are developed based on a simple view of pharmacokinetic half-life and of the oral absorption processes along the gastrointestinal tract. Les has defined a new "operational multiple dosing half-life" that is remarkably sensitive to absorption half-life. While the absorption process is greatly over-simplified when thought of as a first-order process, the concept of an operational half-life for multiple dosing may revolutionize the oral formulation development process for immediate release as well as for controlled or modified release products. This will result in more optimal oral pharmaceutical therapy. It has always been my view that (logically) immediate release dosage forms cannot be optimal for all therapy. These papers provide a path forward to the development of more optimal oral dosage forms and drug dosing and thus more optimal pharmacotherapy.

Finally, Les's contributions to the next level of challenge, pharmacodynamics, adds some of the "system" (whole body) components onto the drug effects on the system processes. The metabolism-transporter interplay no doubt determines the complex distribution and elimination kinetics of a drug in the body and in the tissue (or cell). There can be no doubt that the subcellular distribution and kinetics of a drug molecule is ultimately determined by these same interactions. The receptor site(s) interactions within the cell and integrated throughout the "system" (whole body) is our next level of challenge.

Undoubtedly, Les is not done. Driven by science as few of us are, his contributions to the pharmaceutical and biomedical fields have been major leaps in our understanding of key concepts. These advances, I am confident, will stand the test of time!

\section{REFERENCES}

1. Benet LZ. Noncompartmental determination of the steady-state volume of distribution-the backstory. AAPS J. 2012;14:164-7.

2. Benet LZ, Goyan JE. Determination of the stability constants of tetracycline complexes. J Pharm Sci. 1965;54:983-7.

3. Turner RH, Mehta CS, Benet LZ. Apparent directional permeability coefficients for drug ions: in vitro intestinal perfusion studies. J Pharm Sci. 1970;59:590-5.

4. Benet LZ. General treatment of linear mammilary models with elimination from any compartment as used in pharmacokinetics. J Pharm Sci. 1972;61:536-41.
5. Benet LZ, Galeazzi RL. Noncompartmental determination of the volume of distribution steady-state. J Pharm Sci. 1979;68:1071-4.

6. Rowland M, Benet LZ, Riegelman S. Two-compartment model for a drug and its metabolite: application to acetylsalicylic acid pharmacokinetics. J Pharm Sci. 1970;59:364-7.

7. Rowland M, Benet LZ, Graham GG. Clearance concepts in pharmacokinetics. J Pharmacokinet Biopharm. 1973;1:123-35.

8. Galeazzi RL, Benet LZ, Sheiner LB. Relationship between the pharmacokinetics and pharmacodynamics of procainamide. Clin Pharmacol Ther. 1976;20:278-89.

9. Smith DE, Lin ET, Benet LZ. Absorption and disposition of furosemide in healthy volunteers, measured with a metabolitespecific assay. Drug Metabol Dispos. 1980;8:337-42.

10. Legler UF, Frey FJ, Benet LZ. Prednisolone clearance at steady state in man. J Clin Endocrinol Metab. 1982;55:762-7.

11. Noonan PK, Williams RL, Benet LZ. Dose dependent pharmacokinetics of nitroglycerin after multiple intravenous infusions in healthy volunteers. J Pharmacokinet Biopharm. 1985;13:143-57.

12. Smith PC, McDonagh AF, Benet LZ. Irreversible binding of zomepirac to plasma protein in vitro and in vivo. J Clin Invest. 1986;77:934-9.

13. Nakashima E, Benet LZ. General treatment of mean residence time, clearance, and volume parameters in linear mammillary models with elimination from any compartment. J Pharmacokinet Biopharm. 1988;16:475-92.

14. Harris RZ, Benet LZ, Schwartz JB. Gender effects in pharmacokinetics and pharmacodynamics. Drugs. 1995;50:222-39.

15. Spahn-Langguth H, Benet LZ. Acyl glucuronides revisited: is the glucuronidation process a toxification as well as a detoxification mechanism? Drug Metab Rev. 1992;24:5-47.

16. Wu CY, Benet LZ, Hebert MF, Gupta SK, Rowland M, Gomez DY, et al. Differentiation of absorption and first-pass gut and hepatic metabolism in humans: studies with cyclosporine. Clin Pharmacol Ther. 1995;58:492-7.

17. Fan J, Chen S, Chow EC, Pang KS. PBPK modeling of intestinal and liver enzymes and transporters in drug absorption and sequential metabolism. Curr Drug Metab. 2010;11:743-61.

18. Wacher VJ, Wu CY, Benet LZ. Overlapping substrate specificities and tissue distribution of cytochrome P450 3A and P-glycoprotein: implications for drug delivery and activity in cancer chemotherapy. Mol Carcinog. 1995;13:129-34.

19. Lown KS, Mayo RR, Leichtman AB, Hsiao HL, Turgeon DK, Schmiedlin-Ren P, et al. Role of intestinal P-glycoprotein (mdrl) in interpatient variation in the oral bioavailability of cyclosporine. Clin Pharmacol Ther. 1997;62:248-60.

20. Wacher VJ, Silverman JA, Zhang Y, Benet LZ. Role of Pglycoprotein and cytochrome $\mathrm{P} 4503 \mathrm{~A}$ in limiting oral absorption of peptides and peptidomimetics. J Pharm Sci. 1998;87:1322-30.

21. Schadt EE, Molony C, Chudin E, Hao K, Yang X, Lum PY, et al. Mapping the genetic architecture of gene expression in human liver. PLoS Biol. 2008;6:e107.

22. Cummins CL, Mangravite LM, Benet LZ. Characterizing the expression of CYP3A4 and efflux transporters (P-gp, MRP1, and MRP2) in CYP3A4-transfected Caco-2 cells after induction with sodium butyrate and the phorbol ester 12-O-tetradecanoylphorbol-13-acetate. Pharm Res. 2001;18:1102-9.

23. Benet LZ, Cummins CL. The drug efflux-metabolism alliance: biochemical aspects. Adv Drug Deliv Rev. 2001;50 Suppl 1:S3-1 1.

24. Benet LZ, Cummins CL, Wu CY. Transporter-enzyme interactions: implications for predicting drug-drug interactions from in vitro data. Curr Drug Metab. 2003;4:393-8.

25. Benet LZ, Cummins CL, Wu CY. Unmasking the dynamic interplay between efflux transporters and metabolic enzymes. Int $\mathrm{J}$ Pharm. 2004;277:3-9. 
26. Wu CY, Benet LZ. Predicting drug disposition via application of BCS: transport/absorption/elimination interplay and development of a biopharmaceutics drug disposition classification system. Pharm Res. 2005;22:11-23.

27. Benet LZ. Predicting drug disposition via application of a biopharmaceutics drug disposition classification system. Basic Clin Pharmacol Toxicol. 2010;106:162-7.

28. Broccatelli F, Gruciani G, Benet LZ, Oprea TI. BDDCS class prediction for new molecular entities. Mol Pharm. 2012;9:570-80.

29. Cummins CL, Jacobsen W, Benet LZ. Unmasking the dynamic interplay between intestinal P-glycoprotein and CYP3A4. J Pharmacol Exp Ther. 2002;300:1036-45.

30. Custodio JM, Wu CY, Benet LZ. Predicting drug disposition, absorption/elimination/transporter interplay and the role of food on drug absorption. Adv Drug Deliv Rev. 2008;60:71733

31. Shugarts S, Benet LZ. The role of transporters in the pharmacokinetics of orally administered drugs. Pharm Res. 2009;26:2039-54.

32. Benet LZ, Broccatelli F, Oprea TI. BDDCS applied to over 900 drugs. AAPS J. 2011;13:519-47.
33. Amidon GL, Sinko PJ, Fleisher D. Estimating human oral fraction dose absorbed: a correlation using rat intestinal membrane permeability for passive and carrier-mediated compounds. Pharm Res. 1988;5:651-4.

34. Amidon GL, Lennernäs H, Shah VP, Crison JR. A theoretical basis for a biopharmaceutic drug classification: the correlation of in vitro drug product dissolution and in vivo bioavailability. Pharm Res. 1995;12:413-20.

35. Kasim NA, Whitehouse M, Ramachandran C, Bermejo M, Lennernäs H, Hussain AS, Junginger HE, Stavchansky SA, Midha KK, Shah VP, Amidon GL. Molecular properties of WHO essential drugs and provisional biopharmaceutical classification. Mol Pharm. 2004;1:85-96.

36. Sahin S, Benet LZ. The operational multiple dosing half-life: a key to defining drug accumulation in patients and to designing extended release dosage forms. Pharm Res. 2008;25:2869-77.

37. Grover A, Benet LZ. Intermittent drug dosing intervals guided by the operational multiple dosing half lives for predictable plasma accumulation and fluctuation. J Pharmacokin Pharmacodyn. 2011;38:369-83. 